\title{
THE ILLUMINATOR
}

The illuminator has proved to be a very effective and inexpensive teaching aid. It can be made in a hour or so from odd pieces of wood, card and two wire coat hangers. The light source can be from electric mains power, batteries, oil or gas lights.

When a printed polythene bag is placed over the wire frame and illuminated, it looks like a small overhead projector picture. A4 size polythene bags can be used for small groups of up to eight children, and a larger one for biggerclasses. Felt tipped pens, spirit felt tipped pens and some crayons may be used for drawing on the polythene.

Caution must be used when using this piece of equipment when any of the light sources are used, except the dry battery or the torch bulb. The illuminator may be used without any lights if it is placed before a window.

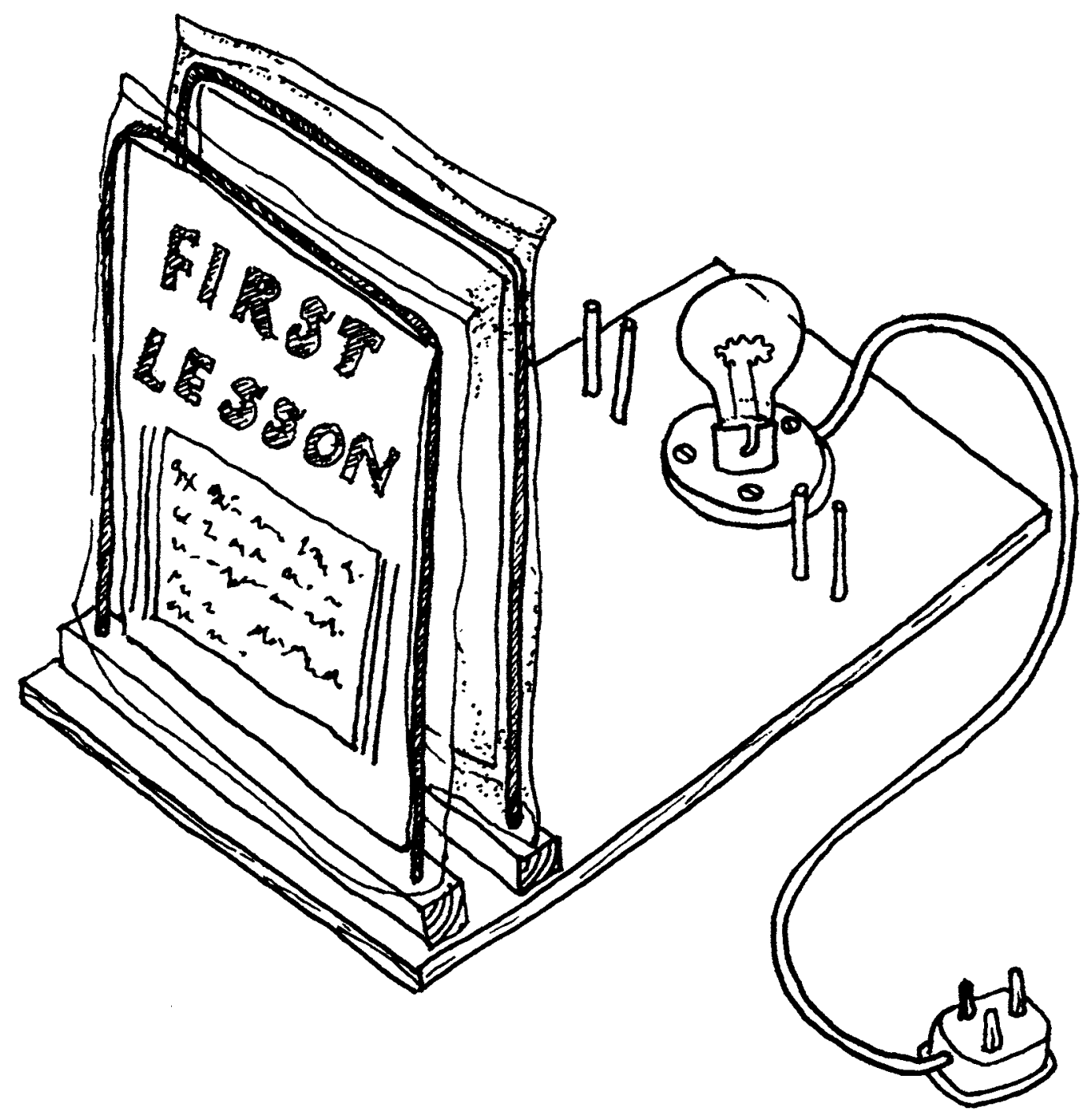




\section{Materials :}

A Baseboard of plywood or wood $10 " \mathrm{x} 12^{\prime \prime} \times \frac{1}{2} "$

B Frame block of softwood $1 " \times 1 " \times 10 "$

C Reflector

D Electric bulb holder

E Electric bulb 60w - 100w

$F$ Length of electric wire

G Electric plug

$\mathrm{H}$ Wire frames, for instance coat hangers

I Reflector - stiff white card
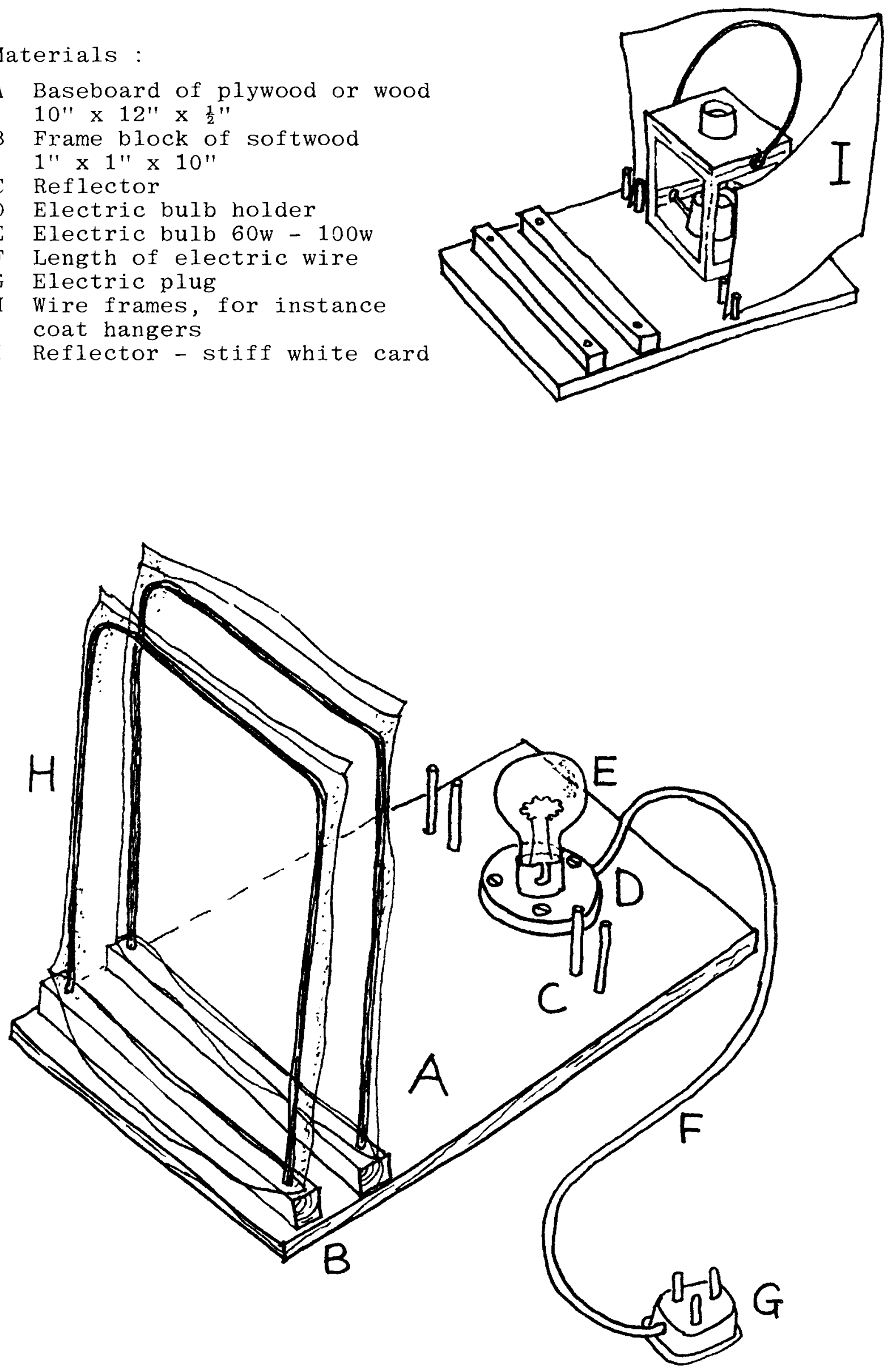

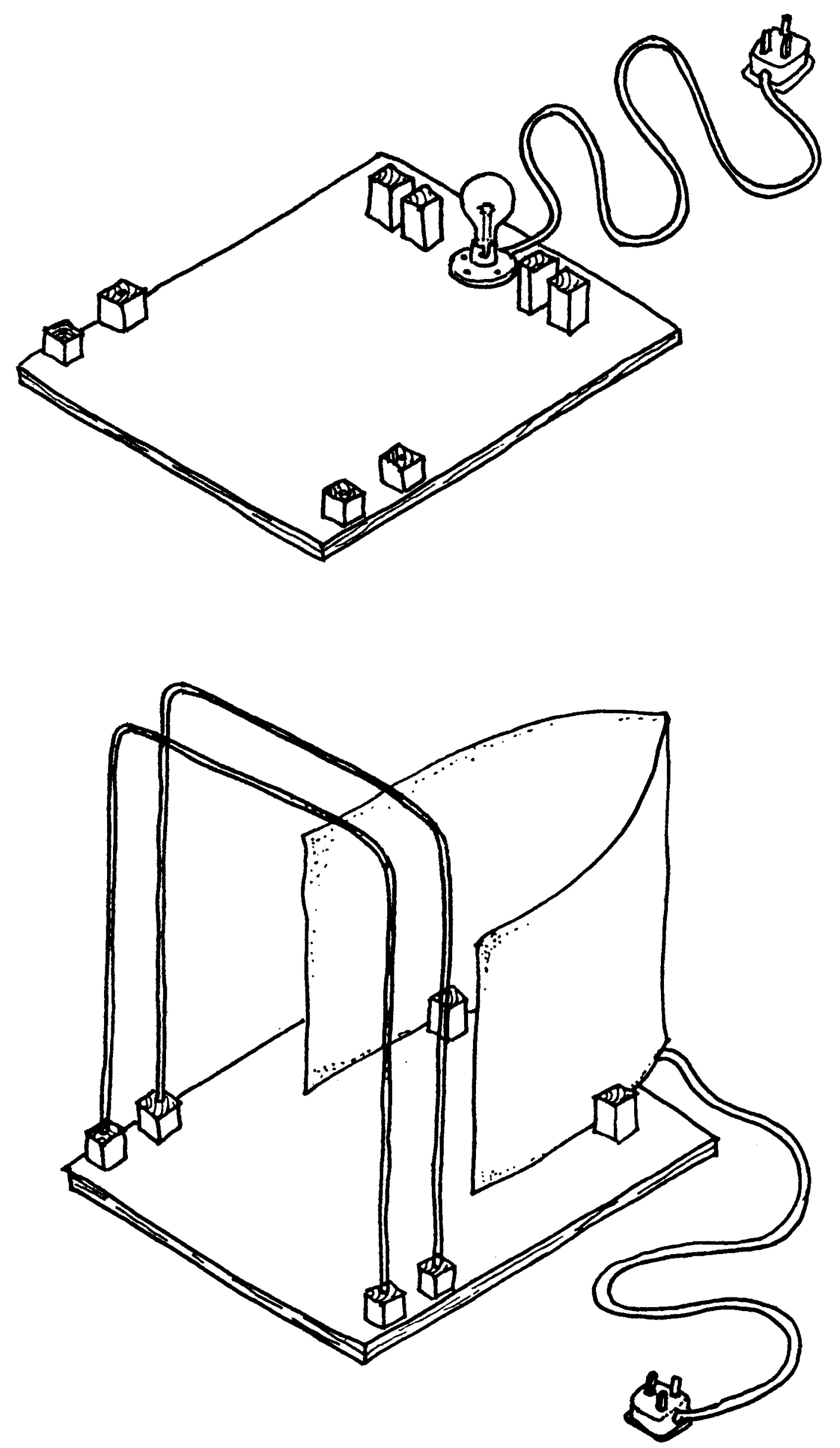

42 